Neonatology 2020;117:411-427

DOI: $10.1159 / 000505519$
Received: September 30, 2019

Accepted after revision: December 18, 2019

Published online: April 1, 2020

\title{
Predictors of Outcomes in Hypoxic- Ischemic Encephalopathy following Hypothermia: A Meta-Analysis
}

\author{
Sabine Ouwehand ${ }^{\mathrm{a}}$ Lisanne C.A. Smidt ${ }^{\mathrm{a}} \quad$ Jeroen Dudink ${ }^{\mathrm{a}, \mathrm{b}}$ \\ Manon J.N.L. Benders ${ }^{a}, b$ Linda S. de Vries ${ }^{a, b}$ Floris Groenendaal ${ }^{a, b}$ \\ Niek E. van der $A a^{a, b}$ \\ ${ }^{a}$ Department of Neonatology, Wilhelmina Children's Hospital, University Medical Center Utrecht, \\ Utrecht, The Netherlands; ${ }^{b}$ UMC Utrecht Brain Center, University Medical Center Utrecht, Utrecht University, \\ Utrecht, The Netherlands
}

\section{Keywords}

Hypoxic-ischemic encephalopathy · Neurodevelopmental outcome $\cdot$ Meta-analysis

\begin{abstract}
Introduction: Prediction of neurodevelopmental outcome in infants with hypoxic-ischemic encephalopathy remains an important challenge. Various studies have shown that the predictive ability of different modalities changed after the introduction of therapeutic hypothermia. This paper reviews the diagnostic test accuracy of the different modalities that are being used to predict neurodevelopmental outcomes following therapeutic hypothermia. Methods: A systematic literature search was performed using Embase and PubMed. Two reviewers independently included eligible studies and extracted data. The quality of the studies was assessed using the Quality in Prognosis Studies Tool. Meta-analyses were performed where possible. Results: Forty-seven articles and 3 conference abstracts were included, reporting on 3,072 infants of whom $39 \%$ died or had an adverse neurodevelopmental outcome. A meta-analysis could be performed using 37 articles on (amplitude-integrated) electroencephalography (EEG), conventional magnetic resonance imaging (MRI), diffusion-weighted imaging (DWI), and proton magnetic
\end{abstract}

karger@karger.com www.karger.com/neo

Karger $\stackrel{\text { ' }}{5}$

GOPEN ACCESS
(C) 2020 The Author(s)

Published by S. Karger AG, Basel

This article is licensed under the Creative Commons AttributionNonCommercial-NoDerivatives 4.0 International License (CC BYNC-ND) (http://www.karger.com/Services/OpenAccessLicense). Usage and distribution for commercial purposes as well as any distribution of modified material requires written permission. resonance spectroscopy (' $\mathrm{H}-\mathrm{MRS})$. Amplitude-integrated EEG (aEEG) at 24 and $72 \mathrm{~h}$ showed similar high diagnostic OR, while aEEG at $6 \mathrm{~h}$ and EEG performed less, both due to a low specificity. For MRI, most studies reported scoring systems in which early ( $<8$ days) MRI performed better than late $(\geq 8$ days) MRI. Injury to the posterior limb of the internal capsule on MRI or to the thalami on DWI were strong individual predictors, as was an increased lactate/ $\mathrm{N}$-acetylaspartate peak on ${ }^{1} \mathrm{H}$-MRS. Conclusions: In the era of therapeutic hypothermia, the different modalities remain good predictors of neurodevelopmental outcome. However, timing should be taken into account. aEEG may initially be false positive and gets more reliable after $24 \mathrm{~h}$. In contrast, MRI should be used during the first week, as its predictive value decreases afterwards.

(c) 2020 The Author(s)

Published by S. Karger AG, Basel

\section{Introduction}

Hypoxic-ischemic encephalopathy (HIE) following perinatal asphyxia is the most common cause of acquired perinatal brain injury and may lead to death or long-term neurologic sequelae $[1,2]$. During the last decade, therapeutic hypothermia $(\mathrm{TH})$ has become standard treatment 
for infants with moderate to severe HIE and it has been shown to reduce both mortality and morbidity [1].

Early prognostication remains challenging but essential for parental counseling and intensive care management, including the use of future neuroprotective strategies. A wide variety of neurophysiologic and neuroimaging modalities are currently available to assess the degree of brain injury and predict long-term outcomes. The predictive value of these tests was first studied as part of large randomized controlled trials [3-5] studying the effect of $\mathrm{TH}$ on outcomes, and many studies have followed since. Following TH, the predictive abilities of some tests have been reported to have changed, although they remain useful tools [6, 7]. Various factors may have contributed to the changed predictive characteristics following $\mathrm{TH}$, including differences in inclusion criteria for studies prior to and during the $\mathrm{TH}$ era and changes in the extent and time course of injury following TH [7].

So far only 1 meta-analysis [8] has reported the predictive characteristics of amplitude-integrated electroencephalography (aEEG) regarding $\mathrm{TH}$ studies only, and no meta-analysis has been performed reporting all neurophysiologic and neuroimaging modalities. Therefore, we performed a systematic review and meta-analysis to provide an overview of the prognostic values of the techniques that are most commonly used in clinical practice for predicting neurodevelopmental outcomes in HIE. Specifically, electroencephalography (EEG), aEEG, nearinfrared resonance spectroscopy (NIRS), evoked potentials, different magnetic resonance imaging (MRI) modalities, and cranial ultrasound (cUS) were evaluated.

\section{Methods}

\section{Information Sources}

We conducted a systematic review and meta-analysis following Preferred Reporting Items for Systematic Reviews and Meta-analyses guidelines [9] and the Meta-Analysis of Observational Studies in Epidemiology [10]. A systematic search was performed in PubMed and Embase by 2 authors (L.C.A.S. and S.O.) on November 29, 2018, and was based on the search by van Laerhoven et al. [11] (online suppl. Fig. 1; for all online suppl. material, see www. karger.com/doi/10.1159/000505519). The reference lists of included studies were screened in order to identify any additional relevant studies. Conference abstracts were also eligible for inclusion to minimize publication bias. When an article or conference abstract lacked the required clinical data or data to perform a metaanalysis, additional data was requested from the authors via e-mail.

\section{Study Eligibility}

Studies were selected based on the following inclusion criteria: (1) studies on term and near-term infants (gestational age $\geq 35$ weeks) with HIE treated with TH; (2) relationship between neurodevelopmental outcomes and at least 1 of the following prognostic tests described: aEEG, EEG, NIRS, evoked potentials, MRI, and cUS; and (3) neurodevelopmental follow-up during at least 18 months. Neurodevelopmental outcomes had to be defined by at least 1 of the following criteria: (1) death, (2) development of cerebral palsy, and (3) developmental outcome using validated tools such as the Bayley Scales of Infant Development. Studies were excluded when there were: (1) no separate results on hypothermic infants if the study contained data on hypothermic and normothermic infants; (2) when the number of infants with outcome data as described above was lower than 15; or (3) when an additional treatment other than TH was investigated. When studies from the same authors reported overlapping populations for the same test, the study with fewer infants was excluded. Studies published in a language other than English, Dutch, French, Spanish, or German were also excluded. Studies that did not provide data for $2 \times 2$ tables after a request to the authors were included in the systematic review but not in the metaanalysis. Conference abstracts were not included for the review if no sufficient clinical data were available after contacting the authors.

\section{Data Extraction}

Information regarding the study design, the setting, the number of included infants and follow-up, infants' baseline characteristics, outcome measurements, prognostic factor methods, and results were independently extracted by 2 of the authors (L.C.A.S. and S.O.) and discussed with a third author (N.E.A.) in case of any doubt. When articles provided data on both abnormal Bayley III scores $<85$ and $<70$, we used $<85$ as indicative of abnormal outcomes, since Bayley III scores have been reported to be higher than Bayley II scores [12]. When articles described separate results for motor and cognitive or language impairment, we chose cognitive impairment for the meta-analysis.

\section{Quality Assessment}

The quality of the included studies was assessed using the Quality in Prognosis Studies Tool on the risk of bias in the following 6 domains: patient selection, study attrition, measurement of prognostic factors, outcome measurements, study confounding, and statistical analysis and reporting [13]. Two reviewers (S.O. and L.C.A.S.) independently rated the methodological quality of each study and in case of disagreement a third author (N.E.A.) was consulted.

\section{Statistical Analysis}

Receiver operating characteristic curve analysis using MedCalc Software (version 19.0.7; Ostend, Belgium) was used to identify the optimal cut-off value when the predictor was reported as continuous data or with more than 2 abnormal classifications (e.g., for MRI scoring methods).

If 3 or more studies reported a predictor of outcome, the predictor was included in the meta-analyses. Meta-analyses were performed using the Meta4Diag package in R (www.r-project.org, version 3.6.0) [14]. The Meta4Diag package allows modelling of pooled logit sensitivity and logit specificity using a bivariate random effects approach with a binomial distribution. This model has been shown to perform better in meta-analysis of diagnostic test accuracy studies, especially when including studies with smaller sample sizes [15]. The diagnostic OR (DOR) was calculated for direct comparison of the diagnostic utility of individual tests 
Table 1. Characteristics of the included studies

\begin{tabular}{|c|c|c|c|c|c|c|c|}
\hline Study & Design & $n / N^{\mathrm{e}}$ & HIE grade g $^{\mathrm{f}}$ & $\begin{array}{l}\text { Follow-up, } \\
\text { months }\end{array}$ & $\begin{array}{l}\text { Adverse } \\
\text { outcome, } \\
\%\end{array}$ & Defined adverse outcome & $\begin{array}{l}\text { Predictor } \\
\text { studied }\end{array}$ \\
\hline Aeby et al. $[30]^{\mathrm{a}, \mathrm{d}}$ & $\mathrm{R}$ & $20 / 20$ & NR & 24 & 35 & Death, BSID-III, SND & aEEG, EEG \\
\hline Al Amrani et al. [71] & $\mathrm{P}$ & $29 / 32$ & NR & 26 & 17 & Developmental delay, CP, PNE & DWI \\
\hline Al Amrani et al. $[51]^{\mathrm{d}}$ & $\mathrm{R}$ & $119 / 130$ & NR & 32 & 23 & Developmental delay, CP, PNE & MRI \\
\hline Alderliesten et al. [68] & $\mathrm{R}$ & $65 / 65$ & $6 / 47 / 12$ & 18 & 28 & Death, Griffiths score $<85, \mathrm{CP}$ & DWI \\
\hline Alderliesten et al. [69] ${ }^{\mathrm{d}}$ & $\mathrm{R}$ & $88 / 88$ & $10 / 62 / 16$ & 24 & 33 & Death, BSID-III <85, CP, SND & DWI, ${ }^{1} \mathrm{H}-\mathrm{MRS}$ \\
\hline Ancora $[53]^{\mathrm{d}}$ & $\mathrm{R}$ & $20 / 20$ & $0 / 16 / 4$ & 24 & 30 & Death, Griffiths score $<88.7, \mathrm{CP}, \mathrm{SND}$ & $\begin{array}{l}\text { MRI, DTI, } \\
{ }^{1} \mathrm{H}-\mathrm{MRS}\end{array}$ \\
\hline Azzopardi et al. $[16]^{\mathrm{d}}$ & $\mathrm{P}$ & $158 / 158$ & NR & 18 & 42 & Death, BSID-II MDI<70, CP 3-5, SND & aEEG \\
\hline Barta $[54]^{\mathrm{d}}$ & $\mathrm{R}$ & $51 / 68$ & $0 / 5 / 46$ & $18-26$ & 31 & Death, BSID-II $<70$ & MRI, ${ }^{1} \mathrm{H}-\mathrm{MRS}$ \\
\hline Burton $[49]^{\mathrm{d}}$ & $\mathrm{R}$ & $19 / 28$ & $\mathrm{NR}$ & 25 & 42 & Mullen or Capute score $<85$, CP 2-5 & NIRS \\
\hline Cainelli et al. [41] & $\mathrm{P}$ & $35 / 35$ & $0 / 35 / 0$ & 24 & 57 & Griffiths score $<85$, also on subscales & EEG, SEP, VEP \\
\hline Chalak et al. $[55]^{\mathrm{d}}$ & $\mathrm{P}$ & $67 / 75$ & $0 / 80 / 10$ & 20 & 54 & Death, BSID-III $<85$, CP & MRI \\
\hline Charon et al. $[56]^{\mathrm{d}}$ & $\mathrm{R}$ & $38 / 43$ & $0 / 17 / 14$ & 24 & 21 & Death, revised Brunet-Lezine score $<70, \mathrm{CP} 3-5$ & MRI, DWI \\
\hline Csekő $[17]^{\mathrm{d}}$ & $\mathrm{R}$ & $70 / 77$ & $14 / 35 / 21$ & $18-24$ & 37 & Death, BSID-II $<70$, CP & $\mathrm{aEEG}$ \\
\hline De Wispelaere $[18]^{\mathrm{d}}$ & $\mathrm{R}$ & $45 / 45$ & $11 / 23 / 11$ & 24 & 51 & Death, BSID-II/III <85, CP 2-5, SND, PNE & aEEG, MRI \\
\hline Del Balzo $[34]^{\mathrm{d}}$ & $\mathrm{R}$ & $20 / 20$ & NR & 18 & 45 & $\begin{array}{l}\text { Death, BSID-III MDI }<55 \text {, inability to walk, sit, feed } \\
\text { one's self or use one's hands, CP, SND }\end{array}$ & EEG, MRI \\
\hline Dereymaeker et al. [42] ${ }^{\mathrm{d}}$ & $\mathrm{R}$ & $19 / 19$ & $\begin{array}{l}9(7-13)^{\mathrm{c}} \\
12(12-14)\end{array}$ & 24 & 53 & Death, BSID-II <70, CP, SND, refractory PNE & EEG \\
\hline Dunne et al. $[35]^{\mathrm{d}}$ & $\mathrm{R}$ & $43 / 49$ & $\mathrm{NR}$ & 24 & 33 & Death, BSID-II, Griffiths score, CP 2-5, SND, PNE & EEG, MRI \\
\hline Fitzgerald et al. $[43]^{\mathrm{d}}$ & $\mathrm{R}$ & $109 / 132$ & $26 / 77 / 29$ & 23 & 24 & $\begin{array}{l}\text { Death, delays in gross or fine motor skills, also } \\
\text { expressive or receptive language skills }\end{array}$ & EEG \\
\hline Garfinkle et al. $[51]^{\mathrm{d}}$ & $\mathrm{P}$ & $26 / 29$ & $0 / 23 / 3$ & 26 & 19 & BSID-III <80, CP 2-5, SND, PNE & MRI. SEP \\
\hline Gerner et al. [74] & $\mathrm{P}$ & $28 / 28$ & NR & $20-32$ & 71 & $\begin{array}{l}\text { Death, Mullen score }<85 \text { or specific Mullen subscale } \\
\text { t score }<40\end{array}$ & cUS \\
\hline Gluckman et al. [19] & $\mathrm{P}$ & $108 / 116$ & NR & 18 & 55 & Death, BSID-II MDI <70, CP 3-5, SND & $\mathrm{aEEG}$ \\
\hline Hamelin et al. [36] & $\mathrm{R}$ & $16 / 16$ & NR & 23 & 31 & Death, transient motor delay, CP, SND & EEG \\
\hline Heursen et al. $[70]^{\mathrm{d}}$ & $\mathrm{P}$ & $54 / 54$ & $10 / 29 / 15$ & 24 & 33 & Death, BSID-III $<70$, CP $2-5$ & DWI \\
\hline Iyer et al. [37] & $\mathrm{R}$ & $16 / 18$ & NR & 18 & 56 & Death, CP, SND, PNE & EEG \\
\hline Lally et al. $[20]^{\mathrm{d}}$ & $\mathrm{P}$ & $190 / 223$ & $37 / 163 / 23$ & 23 & 16 & $\begin{array}{l}\text { Death, BSID-III cognitive/language }<85, \text { CP } 2-5 \text {, } \\
\text { SND, PNE }\end{array}$ & $\begin{array}{l}\text { aEEG, MRI, } \\
\text { DTI, MRS }\end{array}$ \\
\hline Lemmers $[21]^{\mathrm{d}}$ & $\mathrm{P}$ & $39 / 40$ & $\begin{array}{l}10(7-13)^{\mathrm{c}} \\
12(8-14)\end{array}$ & 18 & 33 & Death, Griffiths score $<85$ & aEEG, NIRS \\
\hline $\begin{array}{l}\text { Leroy-Terquem et al. } \\
{[38]^{\mathrm{d}}}\end{array}$ & $\mathrm{R}$ & $40 / 48$ & $0 / 38 / 2$ & 24 & 25 & $\begin{array}{l}\text { Death, World Health Organization disability } \\
\text { score } 0-4, \mathrm{CP}, \mathrm{SND}, \mathrm{PNE}\end{array}$ & EEG, MRI \\
\hline Li et al. $[39]^{\mathrm{d}}$ & $\mathrm{R}$ & $21 / 21$ & $0 / 16 / 5$ & 50 & 48 & Death, K-form developmental test $<70, \mathrm{CP}, \mathrm{SND}$ & $\begin{array}{l}\text { EEG, MRI, } \\
\text { cUS }\end{array}$ \\
\hline Liu et al. $[22]^{\mathrm{d}}$ & $\mathrm{P}$ & $165 / 165$ & NR & 24 & 30 & Death, BSID-III <85, CP 3-5, SND & aEEG \\
\hline Massaro et al. [57] & $\mathrm{P}$ & $42 / 50$ & $0 / 33 / 9$ & $15-31$ & NR & Continuous BSID-II score & MRI, DTI \\
\hline Mitra et al. $[72]^{\mathrm{d}}$ & $\mathrm{R}$ & $55 / 55$ & NR & 24 & 73 & Death, BSID-III $<85$ & DTI, MRS \\
\hline Mulkey et al. $[58]^{\mathrm{d}}$ & $\mathrm{R}$ & $16 / 16$ & NR & 30 & 69 & Delayed milestones, CP, PNE & MRI, DWI \\
\hline Nevalainen et al. [50] & $\mathrm{R}$ & $23 / 24$ & NR & $18-84$ & 35 & Death, Griffiths score, CP, PNE & SEP \\
\hline Niezen et al. $[23]^{\mathrm{d}}$ & $\mathrm{R}$ & $39 / 39$ & $10(6-18)$ & 30 & 33 & Death, BSID-III <70, CP 3-5 & $\begin{array}{l}\text { aEEG, NIRS, } \\
\text { MRI }\end{array}$ \\
\hline Rutherford et al. [4] ${ }^{\mathrm{d}}$ & $\mathrm{P}$ & $63 / 64$ & NR & 18 & 39 & Death, BSID-II MDI <70, CP 3-5, SND & MRI \\
\hline Schreglmann et al. [59] $]^{\mathrm{a}}$ & $\mathrm{R}$ & $49 / 49$ & NR & 27 & 24 & $\begin{array}{l}\text { BSID-III }<85, \mathrm{CP} \text {, child behavioral checklist, } \\
\text { quantitative checklist for autism in toddlers }\end{array}$ & MRI \\
\hline Sewell et al. $[24]^{\mathrm{d}}$ & $\mathrm{P}$ & $49 / 80$ & $0 / 66 / 14$ & 18 & 35 & $\begin{array}{l}\text { Death, BSID-II }<70 \text {, BSID-III cognitive }<85 \text { or } \\
\text { motor }<80\end{array}$ & aEEG \\
\hline Shankaran et al. $[25]^{\mathrm{d}}$ & $\mathrm{P}$ & $57 / 57$ & $0 / 71 / 37$ & $18-22$ & 42 & Death, BSID-II MDI <85, CP 2-5, SND, PNE & $\mathrm{aEEG}$ \\
\hline Shankaran et al. $[60]^{\mathrm{d}}$ & $\mathrm{P}$ & $73 / 73$ & $0 / 54 / 18$ & $18-22$ & 30 & Death, BSID-II MDI<85, CP 2-5, SND, PNE & MRI \\
\hline Shellhaas et al. [26] & $\mathrm{P}$ & $18 / 21$ & NR & 18 & 28 & Death, BSID-III $<85$ & aEEG, NIRS \\
\hline Sijens et al. [73] & $\mathrm{R}$ & $35 / 35$ & $10.2 \pm 2.9$ & 30 & 29 & Death, BSID-III $<85$, CP & ${ }^{1} \mathrm{H}-\mathrm{MRS}$ \\
\hline Skranes et al. [27] ${ }^{\mathrm{d}}$ & $\mathrm{P}$ & $47 / 47$ & $4 / 32 / 11$ & 24 & 32 & Death, BSID-III <85, CP 3-5, SND & aEEG, MRI \\
\hline Takenouchi et al. [28] & $\mathrm{R}$ & $29 / 31$ & $0 / 15 / 14$ & 22 & 52 & Death, BSID-III MDI <85, CP & aEEG \\
\hline Thoresen et al. [6] ${ }^{\mathrm{d}}$ & $\mathrm{P}$ & $43 / 43$ & NR & 18 & 40 & Death, BSID-II MDI <70, CP 3-5, SND & $\mathrm{aEEG}$ \\
\hline
\end{tabular}


Table 1 (continued)

\begin{tabular}{|c|c|c|c|c|c|c|c|}
\hline Study & Design & $n / N^{\mathrm{e}}$ & HIE grade ${ }^{f}$ & $\begin{array}{l}\text { Follow-up, } \\
\text { months }\end{array}$ & $\begin{array}{l}\text { Adverse } \\
\text { outcome, } \\
\%\end{array}$ & Defined adverse outcome & $\begin{array}{l}\text { Predictor } \\
\text { studied }\end{array}$ \\
\hline Trivedi et al. [61 $]^{\mathrm{d}}$ & $\mathrm{P} / \mathrm{R}^{\mathrm{b}}$ & $57 / 57$ & $0 / 46 / 11$ & $18-24$ & 39 & Death, BSID-III $<85$ & MRI \\
\hline Tusor et al. $[62]^{\mathrm{d}}$ & $\mathrm{R}$ & $43 / 49$ & $11(1-20)$ & 24 & 42 & Death, Griffiths score $<76$, CP 3-5, SND & MRI, DTI \\
\hline Vilan et al. [31] $]^{\mathrm{a}, \mathrm{d}}$ & $\mathrm{R}$ & $89 / 89$ & $10.9 \pm 3.2$ & 18 & 38 & Death, Griffiths score $<85$, CP & $\mathrm{aEEG}$ \\
\hline
\end{tabular}

BSID-II/III, Bayley Scales of Infant and Toddler Development, second or third edition; CP, cerebral palsy; P, prospective; MDI, mental developmental index; NR, not reported; PNE, postneonatal epilepsy; R, retrospective; SND, sensorineural deficits. ${ }^{a}$ Conference abstract. ${ }^{b}$ Combined prospective and retrospective. ${ }^{\mathrm{c}}$ Thompson score for favorable and adverse outcomes. ${ }^{\mathrm{d}}$ Included in the meta-analyses. ${ }^{\mathrm{e}}$ Number of infants with neurodevelopmental followup and the total infants enrolled into this study. ${ }^{\mathrm{f}}$ Reported as mild, moderate, or severe; Thompson scores are presented as medians (range) or means \pm SD.

$(\mathrm{DOR}=[$ true positives/false positives $] /[$ false negatives/true negatives]). In contrast to sensitivity and specificity, the DOR is less dependent on the threshold used and therefore more constant.

As the predictive value of a modality may change over time after perinatal asphyxia, separate meta-analyses were performed for the different time points at which the modality was applied. The results of the meta-analyses were demonstrated in forest plots. No indicator of heterogeneity was calculated, but its potential causes were explored.

Some predictors or time points were reported by only 1 or 2 studies. Those studies were not included in the meta-analyses but were reported in a separate forest plot.

\section{Results}

The search identified 1,279 articles after excluding for duplicates. Ninety-nine potentially relevant articles and 26 conference abstracts were identified based on the abstract. After reading the full text, 47 of the 99 articles were included, 41 of which contained data for $2 \times 2$ tables. Additional data was sent by the contacted authors for 4 out of 16 articles and 3 out of 22 conference abstracts. Fortyseven articles and 3 conference abstracts were eventually selected for this systematic review and 37 were eligible for the meta-analysis (online suppl. Fig. 2).

The study characteristics and test classifications are shown in Tables 1 and 2, respectively. Of all of the studies, $40 \%$ had a prospective design. Most studies scored a moderate risk of bias in at least 2 of the graded categories (online suppl. Table 1). The included studies concerned 3,072 infants. The degree of HIE was reported in 30 studies and it was mild in 150, moderate in 1,182, and severe in 386 infants based on the Sarnat score. The median Thompson scores used in 4 studies ranged between 9 and 12. The age at neurodevelopmental follow-up varied between 18 and 84 months and the follow-up rate was $93 \%$. Death or an abnormal neurodevelopmental outcome was seen in $39 \%$ of the infants.

\section{Amplitude-Integrated Electroencephalography}

Seventeen articles reported on aEEG recordings [6, 16-31]. Nine of those articles used the classification for background pattern by Hellström-Westas et al. [32], 3 used the voltage pattern of al Naqueeb et al. [33], and 3 studies used both methods. The classification by Hellström-Westas et al. [32] had higher sensitivity but lower specificity scores in studies using both methods. The predictive value of the aEEG classification was reported at different time points, including during the first $6 \mathrm{~h}$ after birth, throughout the $72 \mathrm{~h}$ of cooling and after rewarming. Ten studies had aEEG recordings during the whole cooling period $[6,17,18,21,23,24,26-28,30]$. The metaanalysis of aEEG at different time points is shown in Figure 1 , and the results of individual studies not included in the meta-analysis in Figure 2. Overall, sensitivity decreased after $36 \mathrm{~h}$ with an increase of specificity. This was reflected by the lowest DOR at $6 \mathrm{~h}$ and the highest DOR at $36 \mathrm{~h}$ ( 9 vs. 101).

Overall, a higher voltage on aEEG was associated with a better outcome. In a number of studies quantitative analyses of the aEEG were performed. Shellhaas et al. [26] used quantified aEEG margins and found that higher lower margins and mean aEEG voltages at $24-48 \mathrm{~h}$ were associated with good outcomes. Three studies quantified the duration until normalization of the aEEG, and they reported that longer times were predictive of poor outcomes $[6,24,27]$. 
Table 2. Characteristics of different predictors studied

\begin{tabular}{|c|c|c|c|}
\hline Study & Predictor & Abnormal definition & $\begin{array}{l}\text { Timing of the } \\
\text { predictor }\end{array}$ \\
\hline \multirow[t]{2}{*}{ Aeby et al. [30] } & aEEG & Voltage classification: moderate or severe suppression (al Naqueeb et al. [33]) & \multirow[t]{2}{*}{$0-96 \mathrm{~h}$} \\
\hline & EEG & $\begin{array}{l}\text { Moderate: discontinuous activity with an interburst interval }<10 \mathrm{~s} \text {, no clear SWC, or clear } \\
\text { asymmetry or asynchrony; major: interburst interval } 10-60 \mathrm{~s} \text {, severe attenuation of } \\
\text { background patterns, or no SWC; inactive: }<10 \mathrm{uV} \text { or interburst interval }>60 \mathrm{~s} \text { (Murray } \\
\text { et al. [45]); presence of a frontal sharp transient }\end{array}$ & \\
\hline Al Amrani 2017 & DTI & $\begin{array}{l}\mathrm{ADC} \text { and FA values in the thalamus, the PLIC, the lentiform nucleus, the frontal and posterior } \\
\mathrm{WM} \text {, and the frontal, parietal, and occipital cortex }\end{array}$ & $\begin{array}{l}\text { Day } 10 \text {, subset } \\
\text { also on days } 1 \text {, } \\
2-3 \text {, and } 30\end{array}$ \\
\hline Al Amrani et al. [71] & MRI & Injury of BGT or watershed injury on T1, T2, or DTI (Barkovich et al. [64]) & Day $11.2 \pm 5.5$ \\
\hline Alderliesten et al. [68] & DWI & ADC values in the $\mathrm{CC}<0.969 \times 10^{-3} \mathrm{~mm}^{2} / \mathrm{s}$ & Day $4.7 \pm 1.3$ \\
\hline \multirow[t]{2}{*}{ Alderliesten et al. [69] } & DWI & ADC values in the $\mathrm{BG}<0.973$ and in the thalamus $<0.871\left(\times 10^{-3} \mathrm{~mm}^{2} / \mathrm{s}\right)$ & \multirow{2}{*}{$\begin{array}{l}\text { Day } 5.1 \pm 0.8^{\mathrm{a}} \\
\text { Day } 3.6 \pm 1.2\end{array}$} \\
\hline & ${ }^{1} \mathrm{H}-\mathrm{MRS}$ & Ratios of peak areas of $\mathrm{N}$-acetylaspartate/choline and lactate/ $\mathrm{N}$-acetylaspartate $(>0.40)$ in BGT & \\
\hline \multirow[t]{3}{*}{ Ancora et al. [53] } & MRI & $\begin{array}{l}\text { Moderate or severe lesions in the BGT and the PLIC, or severe WM on T1, T2, or DTI (Barkovich } \\
\text { et al. [64]) }\end{array}$ & \multirow[t]{3}{*}{ Day $8.3(4-16)$} \\
\hline & DTI & $\begin{array}{l}\text { FA values, mean diffusivity, radial and axial diffusivity in the supratentorial region, the posterior } \\
\text { cranial fossa, the genu and splenium of the CC, caudate, the PLIC, the thalamus, the lenticular } \\
\text { nucleus, optic radiation, and areas from the occipital, frontal, and frontoparietal WM }\end{array}$ & \\
\hline & ${ }^{1} \mathrm{H}-\mathrm{MRS}$ & $\begin{array}{l}\text { Ratio of peak areas of } \mathrm{N} \text {-acetylaspartate/creatine }(\leq 0.67), \mathrm{N} \text {-acetylaspartate/choline }(\leq 1.82) \text {, } \\
\text { myo-inositol/creatine }(\leq 0.76) \text {, myo-inositol/choline, and (lactate+lipids)/N-acetylaspartate in the } \\
\text { left } \mathrm{BG} \text {, and in the mid-brain parietal-occipital cortex and the left frontoparietal WM }\end{array}$ & \\
\hline Azzopardi et al. [16] & $\mathrm{aEEG}$ & $\begin{array}{l}\text { Burst suppression, low voltage, flat trace (Hellström-Westas and Rosén [32], used in the meta- } \\
\text { analysis) } \\
\text { Moderate or severe suppression (al Naqueeb et al. [33]) }\end{array}$ & $<6 \mathrm{~h}$ \\
\hline \multirow[t]{2}{*}{ Barta et al. [54] } & MRI & $\begin{array}{l}\text { Injury to the BGT, the internal capsule, the cortex or white matter on T1, T2, or DWI (Barkovich } \\
\text { et al. [64]) }\end{array}$ & \multirow[t]{2}{*}{$25 \mathrm{~h}(6-96)$} \\
\hline & ${ }^{1} \mathrm{H}-\mathrm{MRS}$ & $\begin{array}{l}\text { Ratio of peak height of myo-inositol/N-acetylaspartate }(>0.680) \text {, N-acetylaspartate/creatine } \\
(<0.780) \text { and myo-inositol/creatine }(>0.627) \text { in the left thalamus; ratio of peak height and area of } \\
\mathrm{N} \text {-acetylaspartate/choline, choline/creatine, myo-inositol/choline, lactate/N-acetylaspartate, } \\
\text { lactate/choline and lactate/creatine }\end{array}$ & \\
\hline Burton et al. [49] & NIRS & $\mathrm{rScO}_{2}$ value (calculated with an $\mathrm{ROC}$ curve: $>89 \%$ ) & $\begin{array}{l}\text { During } \mathrm{TH} \text {, } \\
\text { rewarming, } \\
\text { normothermia }\end{array}$ \\
\hline \multirow[t]{3}{*}{ Cainelli et al. [41] } & EEG & $\begin{array}{l}\text { Moderate: discontinuous activity with interburst intervals }<10 \mathrm{~s} \text {, other types of continuous activ- } \\
\text { ity, clear asymmetry or asynchrony; major: interburst interval of } 10-60 \mathrm{~s} \text {, severe depression, and } \\
\text { no SWC; inactive: activity }<10 \mathrm{uV} \text { and interburst intervals }>60 \mathrm{~s} \text { (Pressler et al. [47]) }\end{array}$ & \multirow[t]{3}{*}{ Day $7(4-14)$} \\
\hline & SEP & Cortical response of N20: unilateral or bilateral absence or delayed & \\
\hline & VEP & $\begin{array}{l}\text { Response absent, severely depressed, poorly reproducible responses or morphology characterized } \\
\text { by absence of the P200 peak and presence of other peaks usually predominantly negative and at a } \\
\text { longer latency }\end{array}$ & \\
\hline Chalak et al. [55] & MRI & $\begin{array}{l}\text { Injury of BGT, ALIC, PLIC, watershed, cerebral hemispheric devastation on T1/T2 or other cere- } \\
\text { bral lesions (NICHD) (calculated with an ROC curve: score 1-3) }\end{array}$ & Day 8 (4-14) \\
\hline \multirow[t]{2}{*}{ Charon et al. [56] } & MRI & $\begin{array}{l}\text { Injury of BGT, abnormal signal of anterior or posterior watershed, diffuse WM abnormalities, } \\
\text { PLIC on T1, T2 or DWI (Barkovich et al. [64], Rutherford et al. [65] for PLIC) }\end{array}$ & \multirow[t]{2}{*}{$\begin{array}{l}\text { Day } 4(3-6) \\
\text { day } 11(7-21)\end{array}$} \\
\hline & DWI & $\begin{array}{l}\text { ADC values (in } \times 10^{-9} \mathrm{~mm}^{2} / \mathrm{s} \text { ) in the PLIC } \leq 0.96 \text {, in the anterolateral thalami } \leq 0.82 \text {, in lentiform } \\
\text { nuclei in the putamen } \leq 1.01 \text {, in the head of caudate nuclei } \leq 1.21 \text {, in the frontal } W M \leq 1.53 \text {, in the } \\
\text { parietal-occipital WM } \leq 1.35 \text {, in the centrum semiovale } \leq 1.13 \text { and in cerebral peduncles in the } \\
\text { brainstem } \leq 1.05\end{array}$ & \\
\hline
\end{tabular}


Table 2 (continued)




Table 2 (continued)

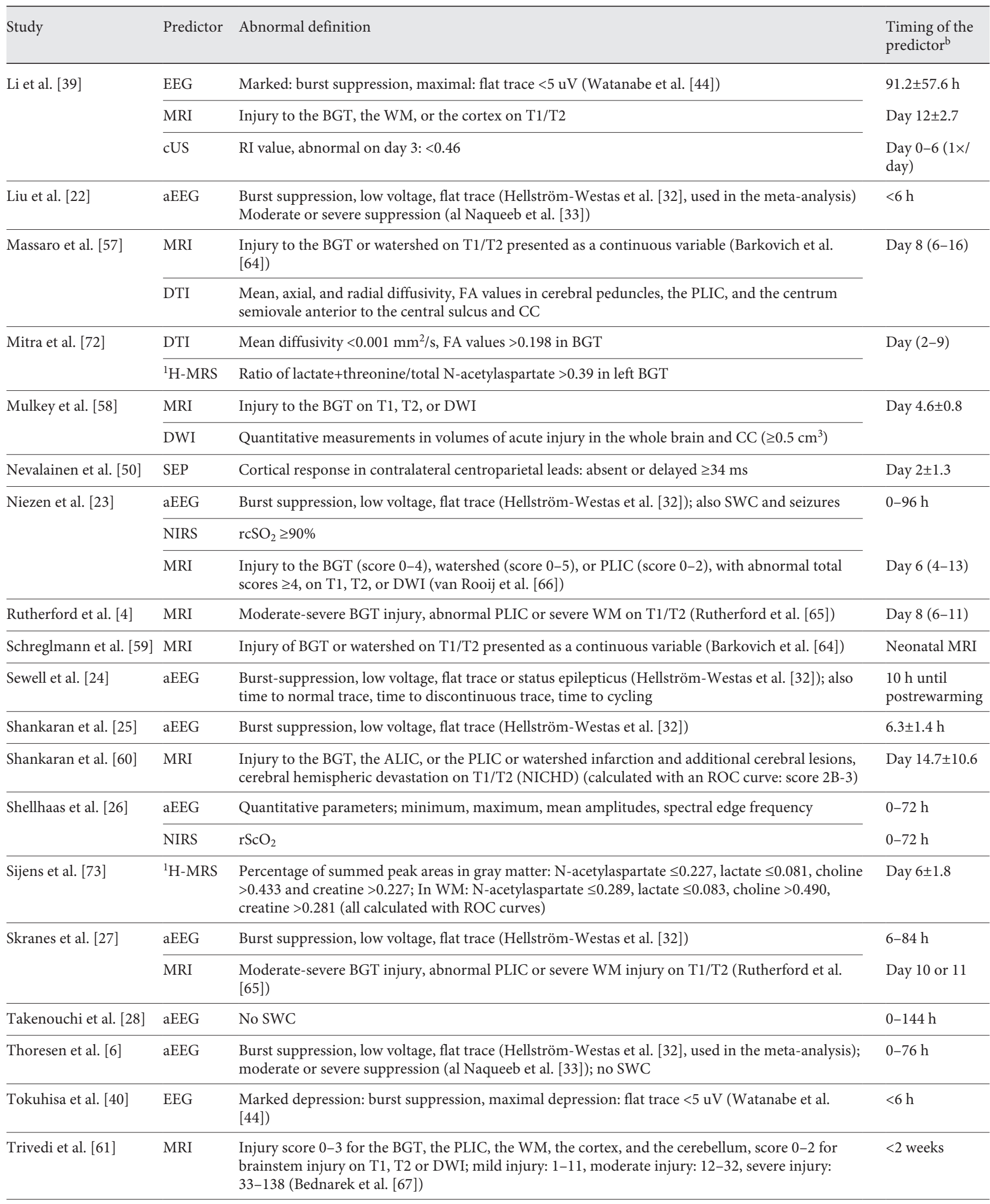


Table 2 (continued)

\begin{tabular}{|c|c|c|c|}
\hline Study & Predictor & Abnormal definition & $\begin{array}{l}\text { Timing of the } \\
\text { predictor }^{\mathrm{b}}\end{array}$ \\
\hline \multirow[t]{2}{*}{ Tusor et al. [62] } & MRI & $\begin{array}{l}\text { Moderate-severe BGT injury, PLIC or severe WM injury on T1, T2, or DTI (Rutherford et al. } \\
\text { [65]) }\end{array}$ & \multirow{2}{*}{$\begin{array}{l}\text { Day } 6 \\
\text { (gestational age } \\
36^{+5}-43^{+1} \\
\text { weeks) }\end{array}$} \\
\hline & DTI & $\begin{array}{l}\text { FA values in the centrum semiovale, the external capsule, the cerebral peduncle, the cingulum, } \\
\text { optic radiation, the inferior longitudinal fasciculus, the ALIC, the PLIC, and the CC }\end{array}$ & \\
\hline Weeke et al. [29] & aEEG & Burst suppression, low voltage, flat trace (Hellström-Westas et al. [32]) & $<6 \mathrm{~h}$ \\
\hline Weeke et al. [63] & MRI & $\begin{array}{l}\text { Score } 0-4 \text { for the BGT, the PLIC, the brainstem, the perirolandic cortex, the hippocampus, the } \\
\text { cortex, the cerebral WM, optic radiation, the CC, punctate WM lesions, parenchymal } \\
\text { hemorrhage, the cerebellum, cerebellar hemorrhage, and } 1 \text { point for intraventricular or subdural } \\
\text { hemorrhages, or sinovenous thrombosis on T1, T2, or DWI; abnormal cut-off } \geq 9.5\end{array}$ & Day $6(5-8)$ \\
\hline
\end{tabular}

Abnormal measurement as provided by the article or used for $2 \times 2$ tables. ALIC, anterior limb of the internal capsule; NICHD, National Institute of Child Health and Human Development. ${ }^{a}$ Timing for favorable and adverse outcomes. ${ }^{b}$ Values are presented as means \pm SD or medians (range).

Development of sleep-wake cycling on aEEG was reported in 5 studies, in which early development of sleepwake cycling was significantly associated with normal outcomes $[6,17,18,23,28]$. Out of the 17 aEEG studies, the conference abstract by Aeby et al. [30] was the only study that reported no association between the aEEG pattern and outcomes. Aeby et al. [30] used the classification of al Naqueeb et al. [33], which was also used by Lally et al. [20] with lower reported sensitivities. The used classification pattern may therefore play a role in the observed heterogeneity for aEEG during the first $6 \mathrm{~h}$ after birth.

\section{Electroencephalography}

Eleven studies reported data on EEG as a predictor of neurodevelopmental outcomes [30, 34-43]. Different EEG scoring systems were used (2 studies used the classification by Watanabe et al. [44], 2 used the classification by Murray et al. [45], 2 used the classification in Lamblin et al. [46], 1 used that of Pressler et al. [47], and another one following the American Clinical Neurophysiology Society guidelines [48]).

Four articles reported continuous EEG recordings during the cooling period [30, 35, 42, 43]. When comparing EEG at different time points in the meta-analysis, sensitivity was comparable at 24 and $48 \mathrm{~h}$ after birth while specificity was slightly lower at $48 \mathrm{~h}$, resulting in a lower DOR. While most studies reported EEG findings during hypothermia, 4 studies reported EEG patterns after hypothermia $[36,38,39,41]$, which were found to be predictive (Fig. 2).

\section{Near-Infrared Spectroscopy}

Four studies focused on the predictive value of NIRS $[21,23,26,49]$, but at different time points, so no metaanalysis was performed. Lemmers et al. [21] calculated the optimal cutoff and found that regional cerebral oxygenation $\left(\mathrm{rScO}_{2}\right)$ values, measured with a small adult transducer, higher than $77 \%$ at $24-48 \mathrm{~h}$ were associated with abnormal neurodevelopmental outcomes. Similarly, Niezen et al. [23] concluded that $\mathrm{rScO}_{2}$ values above $90 \%$ at $48 \mathrm{~h}$ were associated with adverse outcomes. They used a pediatric NIRS sensor. The other articles concluded that $\mathrm{rScO}_{2}$ was not associated with neurodevelopmental outcomes $[26,49]$.

\section{Evoked Potentials}

The use of somatosensory evoked potentials (SEPs) was studied in 3 articles [41, 50,51]. Only Nevalainen et al. [50] performed SEPs during hypothermia, which was found to be predictive. In 2 other studies SEPs were performed after rewarming, but with a lower sensitivity or specificity [41, 51]. In the study by Cainelli et al. [41] both visual evoked potentials and SEPs were performed around day 7 in infants with a normal MRI. They found that visual evoked potentials were a better predictor of outcomes than SEPs.

\section{Magnetic Resonance Imaging}

Twenty-two studies reported scoring methods to assess cerebral injury using T1- and T2-weighted imaging $[4,18,20,23,27,34,35,38,39,51-63]$. Thirteen of those studies also used diffusion-weighted imaging (DWI) or 


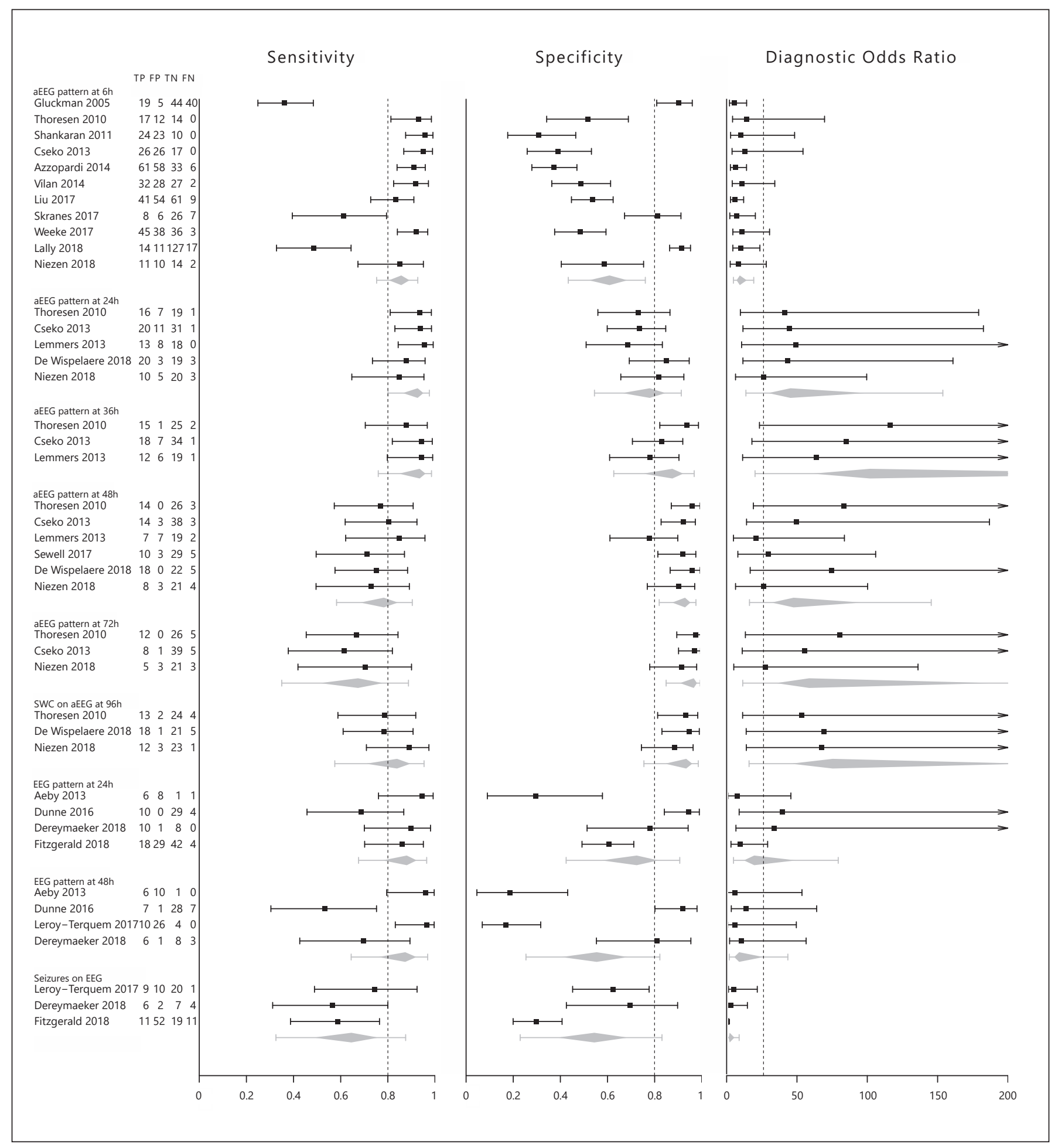

Fig. 1. Meta-analysis of aEEG and EEG at different time points. 


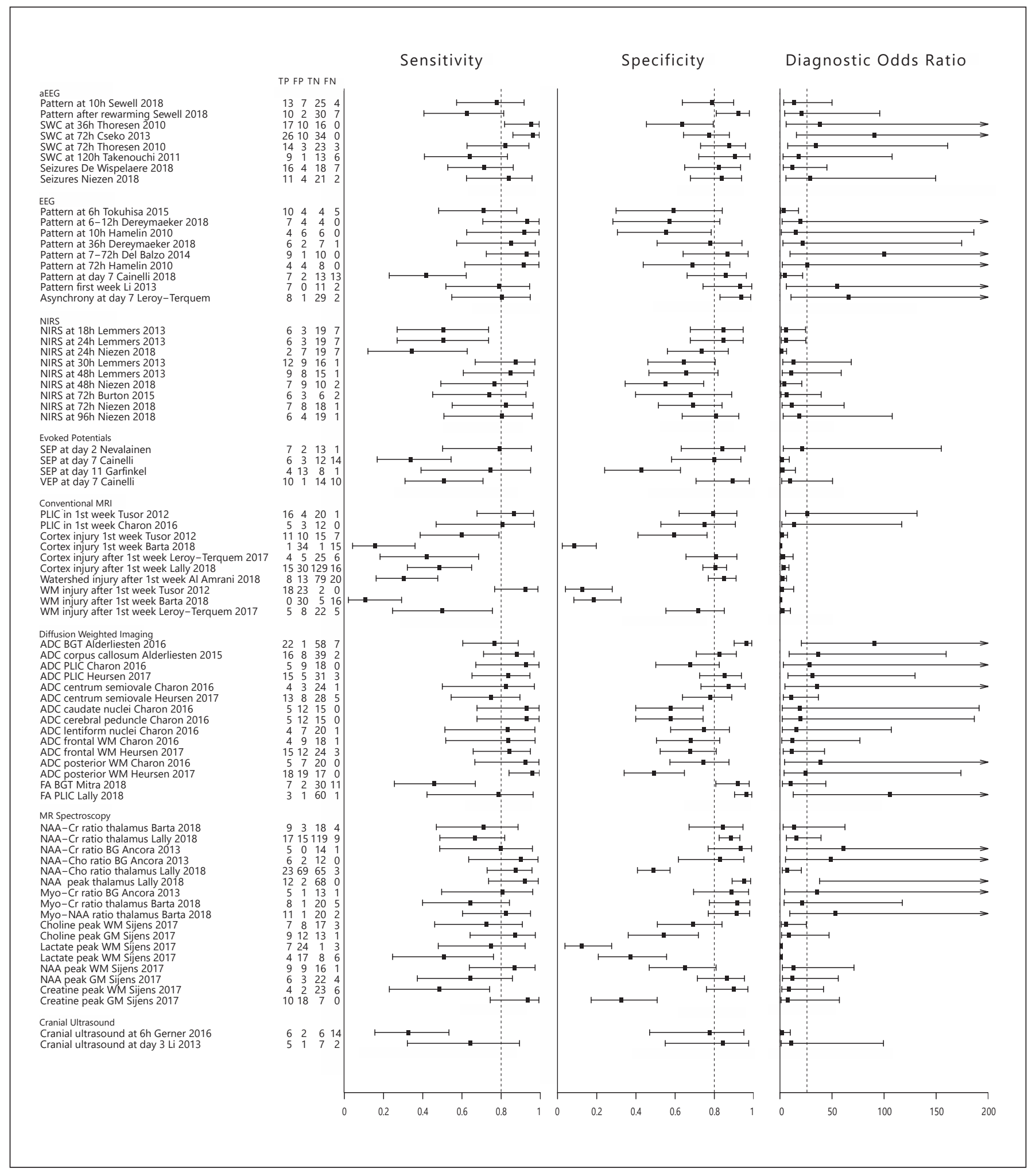

Fig. 2. Results for different modalities that were not included in meta-analyses. 


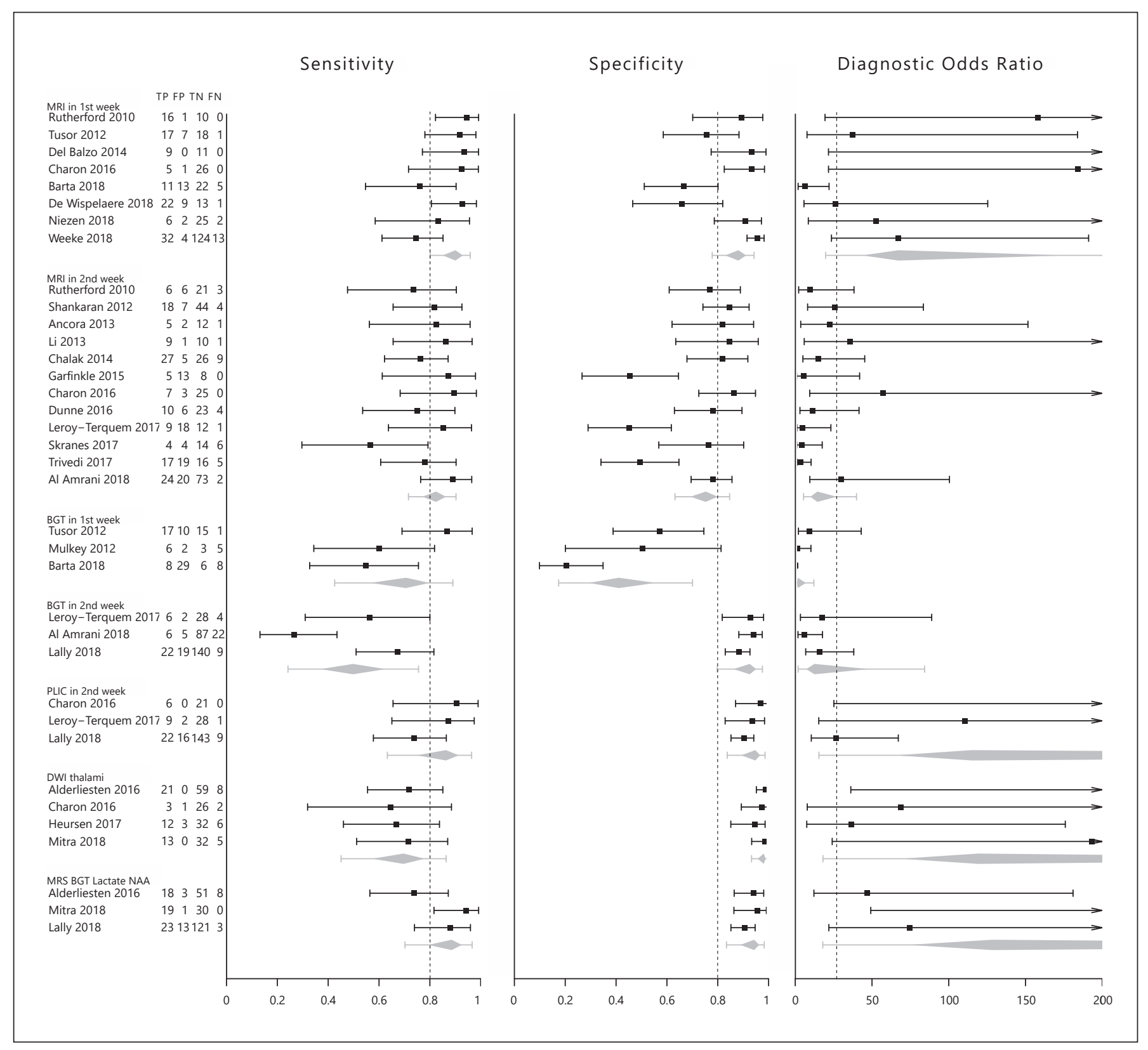

Fig. 3. Meta-analysis of MRI and DWI.

diffusion-tensor imaging (DTI) to assess injury $[18,23$, $34,38,51-54,56,58,61-63]$. Different scoring methods were used, including the Barkovich score in 7 studies [64], the Rutherford score in 6 studies [65], the National Institute of Child Health and Human Development score in 2 studies [60], a score by van Rooij et al. [66] in 2 studies, a score by Bednarek et al. [67] in 1 study, and a new score in the study of Weeke et al. [63]. Four articles did not refer to a previously described scoring method but reported injury to the basal ganglia or thalami (BGT), the posterior limb of the internal capsule (PLIC), the cortex, and the white matter (WM) and/or the watershed regions. The postnatal age at scanning differed between studies, with median ages ranging from the first week to day 15.

The results of the meta-analysis of the studies using a scoring method are shown in Figure 3 and the data of studies not included in the meta-analysis, including those 
reporting injury to individual structures, are depicted in Figure 2. The MRI injury scoring methods were more predictive during the first week than in the second week, with higher sensitivity, specificity and DOR values. This was in line with 2 individual studies, which investigated the timing of conventional MRI. Charon et al. [56] performed MRI on days 4 and 11, and Rutherford et al. [4] performed it before or after day 8 . Both studies reported higher predictive values for the early MRI $[4,56]$.

Meta-analyses could also be performed for injury to the BGT and PLIC on conventional MRI. BGT injury showed a low sensitivity during the first and second week but a high specificity in the second week. Injury to the PLIC, observed in the second week, was found to be very predictive. Only 2 studies reported injury to the PLIC during the first week in relation with outcomes, showing results similar to those reported in the second week [56, 62 ]. Injury to the WM, watershed areas or cortex as individual predictors was found to have a low sensitivity [20, $38,52,54,62]$.

Three studies showed a significant association between MRI injury scores and continuous Bayley scores in cognitive, motor, and language domains [27, 57, 61], whereas Schreglmann et al. [59] found no such association.

\section{Quantitative Analysis of Diffusion Imaging}

Eleven studies performed quantitative analyses on diffusion imaging data, i.e., 5 using DWI within the first week of life $[56,58,68-70]$ and 6 using DTI $[20,53,57$, $62,71,72]$. Multiple studies reported that lower apparent diffusion coefficient (ADC) values during the first 7-10 days were associated with adverse outcomes. This included lower ADC values in the basal ganglia $[69,72]$, the centrum semiovale $[56,70]$, the caudate nucleus [53], the PLIC $[53,56,70,71]$, the frontal or parietal WM $[53,70]$, and the posterior WM [56]. DWI of the thalami could be included in the meta-analyses. ADC values of the thalami were especially useful for identifying those with a good outcome (showing normal ADC values) with a high specificity and a DOR of 119. Injury to the (posterior part of the) corpus callosum was related to adverse outcomes in 3 studies $[53,58,68]$. ADC values in the cerebellum and brainstem [70], as well as cortical ADC values [71], were not related to outcomes.

Al Amrani et al. [71] analyzed DTI data acquired at different time points during the first months after birth. In the adverse outcome group, ADC values in the BGT and PLIC were significantly lower on days $2-3$, followed by significantly higher values on day 10 . On days $6-10$, frac- tional anisotropy values were significantly lower in the PLIC $[20,53,62,71]$, the anterior limb of the internal capsule [62], the corpus callosum [53, 57, 62], the corticospinal tract [57], the frontal WM $[53,62]$, and the BGT in the adverse outcome group in 2 out of 3 studies [53, 71, 72].

\section{Proton Magnetic Resonance Spectroscopy}

Six studies used proton magnetic resonance spectroscopy $\left({ }^{1} \mathrm{H}\right.$-MRS) as a predictor of neurodevelopmental outcomes with different types of metabolites and regions of interest [20, 53, 54, 69, 72, 73]. The lactate/ $\mathrm{N}$-acetylaspartate (NAA) ratio in the BGT was included in the meta-analyses and it was associated with adverse outcomes with a DOR of 18 . NAA/choline ratios in the BGT were not associated with outcomes in one study [69] but it was moderately associated with outcomes in another study [20]. Ancora et al. [53] also studied the basal ganglia and reported lower NAA and higher lactate and myo-inositol ratios in infants with adverse outcomes [53]. Sijens et al. [73] only found significantly lower NAA in the gray matter of infants who died [73]. A study by Barta et al. [54] studied 36 different metabolites in the thalamus, in which myo-inositol/NAA ratios had the strongest correlation with outcomes [54].

\section{Ultrasonography}

Resistive indices (RI) in transfontanellar duplex ultrasonography as a measurement of outcome prediction was studied in 2 articles $[39,74]$. A RI below 0.60 prior to the start of TH was significantly associated with abnormal outcomes according to Gerner et al. [74]. In that study, the RI after cooling was only significantly positively correlated to the raw gross motor function measure score but not to abnormal outcomes. Another study demonstrated significantly lower RI values in the adverse outcome group, with a RI value $<0.46$ on day 3 [39]. No studies reported on the predictive value of cerebral injury observed using ultrasound.

\section{Discussion}

In this article we have reviewed, and where possible performed meta-analyses of the currently used neurophysiologic and neuroimaging techniques for the prediction of neurodevelopmental outcomes following HIE and $\mathrm{TH}$. In contrast to previous meta-analyses, we have also statistically compared the diagnostic characteristics of the different modalities. The best predictors of outcomes were aEEG at $36 \mathrm{~h}$, PLIC abnormalities on MRI, ADC 
values of the thalamus, and MRS of the BGT. Early MRI was more predictive than MRI performed after the first week of life. This is relevant for clinical practice, since early prognostication is preferred.

According to our findings, aEEG had the highest DOR at $36 \mathrm{~h}$. The prognostic utility of aEEG at 24 and $72 \mathrm{~h}$ was similar to that of EEG at $24 \mathrm{~h}$. The least predictive were aEEG at $6 \mathrm{~h}$ and EEG at $48 \mathrm{~h}$, reflected by the lower DOR. aEEG at $6 \mathrm{~h}$ did have a high sensitivity, however, which may be more important than a high specificity at this early stage in order to identify infants potentially at risk for an adverse outcome.

EEG was found not to be superior to a single- or 2-channel aEEG. This could be due to differences in the length of recording, as we found that aEEG was more often recorded continuously compared to EEG. The conference abstract by Aeby et al. [30] was the only study using both methods, in which the aEEG was not related to outcomes and EEG had sensitivity and specificity scores of 100 and $9 \%$, respectively. However, that study included only 20 infants and not all infants had an EEG.

The American College of Obstetricians and Gynecologists guideline on HIE advises MRI between 24 and $96 \mathrm{~h}$ after birth to delineate the timing of the injury, whereas MRI 10 days after birth is recommended for optimal delineation of the extent of the injury [75]. While we did not study which time point is best for identifying the extent of the injury, we found that early MRI (up to day 7) had a better predictive value than late MRI (beyond the first week). As most studies used a scoring method, describing which areas are involved, this suggests that the optimal time point for delineation of the extent of injury may also be in the first week.

Many studies included DWI in their injury scoring method as it allows detection of ischemic injury during the first 7-10 days after the hypoxic event. The age at scan in the later MRI group ranged from 8 to 21 days. DWI abnormalities may still be present early in the second week, while changes in $\mathrm{T} 1$ and $\mathrm{T} 2$ will take time to evolve. The diagnostic information of an MRI on day 8 is therefore different from an MRI acquired on day 14, which was confirmed in our meta-analyses. This was also demonstrated by 2 studies that compared early and late MRI [4, 56]. It is therefore recommended to perform MRI including DWI and ${ }^{1} \mathrm{H}$-MRS during the first week after birth, preferably after rewarming as TH slows the evolution of diffusion abnormalities.

Injury to the PLIC diagnosed in the first or second week after birth was found to be predictive for abnormal outcomes. This was, however, partially influenced by the study of Charon [56], which reported no false-negative or false-positive cases. The large study of Lally et al. [20] reported a lower sensitivity of injury to the PLIC.

DWI abnormalities were quantified using ADC values in a number of studies. Meta-analyses of decreased ADC values in the thalami resulted in a DOR above 100. Similarly, other studies reporting decreased ADC values in other structures such as the PLIC and the corpus callosum were found to be predictive (Fig. 2). It is therefore highly recommended to include DWI in the standard MRI protocol, as it can be used to assess the extent of injury in an MRI score or quantify the ADC values.

The ${ }^{1} \mathrm{H}$-MRS derived lactate-NAA ratio was similarly predictive, as also reported by Alderliesten et al. [69], who compared both methods.

Meta-analyses could not be performed for studies reporting evoked potentials, NIRS, or cUS. SEPs were the most frequently reported evoked potentials and reflect the integrity of the somatosensory pathway. Outcomes may also be poor without injury to these pathways, which may explain the reported low predictive value of SEPs, especially at later time points.

The studies on NIRS reported that a high cerebral oxygenation is associated with adverse outcomes. In the studies of Lemmers et al. [21] and Niezen et al. [23], the majority of the infants with an adverse outcome died, most likely due to very severe brain injury resulting in a low cerebral metabolism and high cerebral oxygenation. The predictive value of NIRS for neurodevelopmental outcomes in those surviving the neonatal period seems limited.

We found no studies reporting the pattern of injury on cUS in relation to outcomes. As cUS can be easily used at the bedside and it can be used sequentially, it would be interesting to study its predictive value in this population.

In this review we focused on the diagnostic modalities, including neurophysiological or neuroimaging modalities, that can be used to predict outcomes. Some studies have also reported other predictors, such as biochemical biomarkers, physical examinations, or heartrate variability. We decided not to include these in the current review but, given the increasing number of papers on these predictors, they might be included in future reviews.

\section{Comparison to Previous Reviews}

Chandrasekaran et al. [8] performed a meta-analysis on aEEG in the cooling era concerning different postnatal time points and included 9 studies [8]. They found the highest diagnostic OR (i.e., 67) at $48 \mathrm{~h}$ after birth. This is comparable to our results, as they only reported aEEG at 
24 and $48 \mathrm{~h}$ and not at $36 \mathrm{~h}$. Chandrasekaran et al. [8] included studies with less than 15 infants and a neurodevelopmental follow-up of 12 months. We only included studies with at least 18 months of follow-up, as development of motor deficits may be difficult to diagnose before this age $[76,77]$.

Del Río et al. [78] also performed a meta-analysis on aEEG including studies with and without $\mathrm{TH}$ and a follow-up time of 12 months. They found the optimal timing of aEEG to be at $72 \mathrm{~h} \mathrm{[78].} \mathrm{A} \mathrm{meta-analysis} \mathrm{on} \mathrm{conven-}$ tional MRI performed by Sánchez Fernández et al. [79] included 5 studies with TH and reported an OR of 14 for an abnormal neonatal MRI predicting unfavorable neurodevelopmental outcomes [79]. They did not, however, analyze timing of MRI. A meta-analysis on ${ }^{1} \mathrm{H}$-MRS by Zou et al. [80] revealed potential predictive values of $\mathrm{NAA} /$ creatine and NAA/choline in BGT and also myoinositol/choline in the cerebral cortex for adverse outcomes [80]. However, the meta-analysis only included 2 studies with $\mathrm{TH}$ patients, which were also included in our study.

\section{Strengths and Weaknesses}

This review provides an overview of the published literature up to now. However, there are several limitations that need to be addressed. Firstly, we observed a high level of heterogeneity among the included studies. This was mainly due to the use of different outcome classifications, definitions of abnormal test measurements, and timing of the test. We therefore performed the meta-analysis on data with similar timing in an attempt to reduce heterogeneity. Another limitation is a small sample size, including 28 studies with a study population of less than 50 infants.

Finally, the presence of bias is also a concern when performing a systematic review. To minimize bias we chose not to eliminate studies if they were not eligible for the meta-analysis, but we included them for the review. Inclusion of conference abstracts for the meta-analysis might prevent publication bias, but it also results in inclusion of abstracts with limited information and of which the study design and results have not been peer-reviewed. normalities on MRI, ADC values of the thalamus, and MRS are most predictive of adverse (neurodevelopmental) outcomes. According to our findings, aEEG at 24-

$72 \mathrm{~h}$ and EEG at 24 and $72 \mathrm{~h}$ after birth were superior to aEEG at $6 \mathrm{~h}$ and EEG at $48 \mathrm{~h}$. Early conventional MRI in the first week of life was preferred over late MRI.

Future studies might benefit from combining neurophysiological and neuroimaging modalities such as aEEG between $24-48 \mathrm{~h}$ and early MRI to further improve prediction of outcomes. Combining diagnostic modalities in the neonatal period with neurological examination on early follow-up has been shown to result in very accurate prediction of outcomes in other neonatal populations at risk for adverse outcomes and warrant further studies in infants with HIE [81].

\section{Statement of Ethics}

This study was conducted ethically according to the World Medical Association Declaration of Helsinki.

\section{Disclosure Statement}

The authors have no conflict of interests to declare.

\section{Funding Sources}

No funding was secured for this study.

\section{Author Contributions}

S.O. conceptualized and designed this study, collected data, and drafted the initial version of this paper. L.C.A.S. conceptualized and designed this study and collected data. N.E.A. conceptualized and designed this study, supervised data collection, performed the analysis, and reviewed and revised this paper. F.G. conceptualized and designed this study, performed the analysis, and reviewed and revised this paper. L.S.V., M.J.B., and J.D. conceptualized and designed this study and reviewed and revised this paper. All of the authors approved the final version of this paper as submitted and agree to be accountable for all aspects of this work.

\section{Conclusions}

This meta-analysis shows that aEEG at $36 \mathrm{~h}$, PLIC ab-

References
Neonatology 2020;117:411-427 DOI: $10.1159 / 000505519$
Ouwehand/Smidt/Dudink/Benders/ de Vries/Groenendaal/van der Aa
1 Jacobs SE, Berg M, Hunt R, Tarnow-Mordi WO, Inder TE, Davis PG. Cooling for newborns with hypoxic ischaemic encephalopathy. Cochrane Database Syst Rev. 2013 Jan;(1):CD003311.

2 Kurinczuk JJ, White-Koning M, Badawi N. Epidemiology of neonatal encephalopathy and hypoxic-ischaemic encephalopathy. Early Hum Dev. 2010 Jun;86(6):329-38. 
3 Cheong JL, Coleman L, Hunt RW, Lee KJ, Doyle LW, Inder TE, et al.; Infant Cooling Evaluation Collaboration. Prognostic utility of magnetic resonance imaging in neonatal hypoxic-ischemic encephalopathy: substudy of a randomized trial. Arch Pediatr Adolesc Med. 2012 Jul;166(7):634-40.

4 Rutherford M, Ramenghi LA, Edwards AD, Brocklehurst $\mathrm{P}$, Halliday $\mathrm{H}$, Levene $\mathrm{M}$, et al. Assessment of brain tissue injury after moderate hypothermia in neonates with hypoxicischaemic encephalopathy: a nested substudy of a randomised controlled trial. Lancet Neurol. 2010 Jan;9(1):39-45.

5 Shankaran S, McDonald SA, Laptook AR, Hintz SR, Barnes PD, Das A, et al.; Eunice Kennedy Shriver National Institute of Child Health and Human Development Neonatal Research Network. Neonatal Magnetic Resonance Imaging Pattern of Brain Injury as a Biomarker of Childhood Outcomes following a Trial of Hypothermia for Neonatal Hypoxic-Ischemic Encephalopathy. J Pediatr. 2015 Nov; 167(5):987-93.e3.

6 Thoresen M, Hellström-Westas L, Liu X, de Vries LS. Effect of hypothermia on amplitude-integrated electroencephalogram in infants with asphyxia. Pediatrics. 2010 Jul; 126(1):e131-9.

7 Sabir H, Cowan FM. Prediction of outcome methods assessing short- and long-term outcome after therapeutic hypothermia. Semin Fetal Neonatal Med. 2015 Apr;20(2):115-21.

8 Chandrasekaran M, Chaban B, Montaldo P, Thayyil S. Predictive value of amplitude-integrated EEG (aEEG) after rescue hypothermic neuroprotection for hypoxic ischemic encephalopathy: a meta-analysis. J Perinatol. 2017;37(6):684-9.

9 McInnes MD, Moher D, Thombs BD, McGrath TA, Bossuyt PM, Clifford T, et al.; and the PRISMA-DTA Group. Preferred Reporting Items for a Systematic Review and Metaanalysis of Diagnostic Test Accuracy Studies: the PRISMA-DTA Statement. JAMA. 2018 Jan;319(4):388-96.

10 Stroup DF, Berlin JA, Morton SC, Olkin I, Williamson GD, Rennie D, et al. Meta-analysis of observational studies in epidemiology: a proposal for reporting. Meta-analysis Of Observational Studies in Epidemiology (MOOSE) group. JAMA. 2000 Apr;283(15): 2008-12.

11 van Laerhoven $H$, de Haan TR, Offringa $M$, Post B, van der Lee JH. Prognostic tests in term neonates with hypoxic-ischemic encephalopathy: a systematic review. Pediatrics. 2013 Jan;131(1):88-98.

12 Jary S, Whitelaw A, Walløe L, Thoresen M. Comparison of Bayley-2 and Bayley-3 scores at 18 months in term infants following neonatal encephalopathy and therapeutic hypothermia. Dev Med Child Neurol. 2013 Nov; 55(11):1053-9.
13 Hayden JA, van der Windt DA, Cartwright JL, Côté P, Bombardier C. Assessing bias in studies of prognostic factors. Ann Intern Med. 2013 Feb;158(4):280-6.

14 Guo J, Riebler A. Meta4diag: Bayesian bivariate meta-analysis of diagnostic test studies for routine practice. J Stat Softw. 2018;83:2018.

15 Hamza TH, Reitsma JB, Stijnen T. Meta-analysis of diagnostic studies: a comparison of random intercept, normal-normal, and binomial-normal bivariate summary ROC approaches. Med Decis Making. 2008 Sep-Oct; 28(5):639-49.

16 Azzopardi D; TOBY study group. Predictive value of the amplitude integrated EEG in infants with hypoxic ischaemic encephalopathy: data from a randomised trial of therapeutic hypothermia. Arch Dis Child Fetal Neonatal Ed. 2014 Jan;99(1):F80-2.

17 Csekő AJ, Bangó M, Lakatos P, Kárdási J, Pusztai L, Szabó M. Accuracy of amplitudeintegrated electroencephalography in the prediction of neurodevelopmental outcome in asphyxiated infants receiving hypothermia treatment. Acta Paediatr. 2013 Jul;102(7): 707-11.

18 De Wispelaere LA, Ouwehand S, Olsthoorn $\mathrm{M}$, Govaert P, Smit LS, de Jonge RC, et al. Electroencephalography and brain magnetic resonance imaging in asphyxia comparing cooled and non-cooled infants. Eur J Paediatr Neurol. 2019 Jan;23(1):181-90.

19 Gluckman PD, Wyatt JS, Azzopardi D, Ballard R, Edwards AD, Ferriero DM, et al. Selective head cooling with mild systemic hypothermia after neonatal encephalopathy: multicentre randomised trial. Lancet. 2005 Feb; 365(9460):663-70.

20 Lally PJ, Montaldo P, Oliveira V, Soe A, Swamy R, Bassett P, et al.; MARBLE consortium. Magnetic resonance spectroscopy assessment of brain injury after moderate hypothermia in neonatal encephalopathy: a prospective multicentre cohort study. Lancet Neurol. 2019 Jan;18(1):35-45.

21 Lemmers PM, Zwanenburg RJ, Benders MJ, de Vries LS, Groenendaal F, van Bel F, et al. Cerebral oxygenation and brain activity after perinatal asphyxia: does hypothermia change their prognostic value? Pediatr Res. 2013 Aug; 74(2):180-5

22 Liu X, Jary S, Cowan F, Thoresen M. Reduced infancy and childhood epilepsy following hypothermia-treated neonatal encephalopathy. Epilepsia. 2017 Nov;58(11):1902-11.

23 Niezen CK, Bos AF, Sival DA, Meiners LC, Ter Horst HJ. Amplitude-Integrated EEG and Cerebral Near-Infrared Spectroscopy in Cooled, Asphyxiated Infants. Am J Perinatol. 2018 Jul;35(9):904-10.

24 Sewell EK, Vezina G, Chang T, Tsuchida T, Harris K, Ridore M, et al. Evolution of Amplitude-Integrated Electroencephalogram as a Predictor of Outcome in Term Encephalopathic Neonates Receiving Therapeutic Hypothermia. Am J Perinatol. 2018 Feb;35(3): 277-85.
25 Shankaran S, Pappas A, McDonald SA, Laptook AR, Bara R, Ehrenkranz RA, et al.; Eunice Kennedy Shriver National Institute of Child Health and Human Development Neonatal Research Network. Predictive value of an early amplitude integrated electroencephalogram and neurologic examination. Pediatrics. $2011 \mathrm{Jul} ; 128(1): \mathrm{e} 112-20$

26 Shellhaas RA, Kushwaha JS, Plegue MA, Selewski DT, Barks JD. An evaluation of cerebral and systemic predictors of 18 -month outcomes for neonates with hypoxic ischemic encephalopathy. J Child Neurol. 2015 Oct; 30(11):1526-31.

27 Skranes JH, Løhaugen G, Schumacher EM, Osredkar D, Server A, Cowan FM, et al. Amplitude-integrated electroencephalography improves the identification of infants with encephalopathy for therapeutic hypothermia and predicts neurodevelopmental outcomes at 2 years of age. J Pediatr. 2017 Aug;187:3442.

28 Takenouchi T, Rubens EO, Yap VL, Ross G, Engel M, Perlman JM. Delayed onset of sleepwake cycling with favorable outcome in hypothermic-treated neonates with encephalopathy. J Pediatr. 2011 Aug; 159(2):232-7.

29 Weeke LC, Vilan A, Toet MC, van Haastert IC, de Vries LS, Groenendaal F. A Comparison of the Thompson Encephalopathy Score and Amplitude-Integrated Electroencephalography in Infants with Perinatal Asphyxia and Therapeutic Hypothermia. Neonatology. 2017;112(1):24-9.

30 Aeby A, Khabbache K, Van Overmeire B, Vermeylen D, Van Bogaert P. Prognostic value of conventional EEG in asphyxiated term newborns treated with hypothermia: experience in 20 cases. Eur J Paediatr Neurol. 2013; 17:S25.

31 Vilan A, De Vries LS, Sá-Couto P, Van Haastert IC, Koopman-Esseboom C, Toet MC, et al. Comparison of clinical and electrophysiological signs of encephalopathy in neonates with perinatal asphyxia qualifying for hypothermia. Arch Dis Child. 2014;99:A167.

32 Hellström-Westas L, Rosén I. Continuous brain-function monitoring: state of the art in clinical practice. Semin Fetal Neonatal Med. 2006 Dec;11(6):503-11.

33 al Naqeeb N, Edwards AD, Cowan FM, Azzopardi D. Assessment of neonatal encephalopathy by amplitude-integrated electroencephalography. Pediatrics. 1999 Jun;103(6 Pt 1):1263-71.

34 Del Balzo F, Maiolo S, Papoff P, Giannini L, Moretti C, Properzi E, et al. Electroencephalogram and magnetic resonance imaging comparison as a predicting factor for neurodevelopmental outcome in hypoxic ischemic encephalopathy infant treated with hypothermia. Pediatr Rep. 2014 Oct;6(3):5532. 
35 Dunne JM, Wertheim D, Clarke P, Kapellou O, Chisholm P, Boardman JP, et al. Automated electroencephalographic discontinuity in cooled newborns predicts cerebral MRI and neurodevelopmental outcome. Arch Dis Child Fetal Neonatal Ed. 2017 Jan;102(1):F5864.

36 Hamelin S, Delnard N, Cneude F, Debillon T, Vercueil L. Influence of hypothermia on the prognostic value of early EEG in full-term neonates with hypoxic ischemic encephalopathy. Neurophysiol Clin. 2011 Feb;41(1):1927.

37 Iyer KK, Roberts JA, Metsäranta M, Finnigan S, Breakspear M, Vanhatalo S. Novel features of early burst suppression predict outcome after birth asphyxia. Ann Clin Transl Neurol. 2014 Mar;1(3):209-14.

38 Leroy-Terquem E, Vermersch AI, Dean P, Assaf Z, Boddaert N, Lapillonne A, et al. Abnormal Interhemispheric Synchrony in Neonatal Hypoxic-Ischemic Encephalopathy: A Retrospective Pilot Study. Neonatology. 2017; 112(4):359-64.

39 Li J, Funato M, Tamai H, Wada H, Nishihara $\mathrm{M}$, Iwamoto $\mathrm{H}$, et al. Predictors of neurological outcome in cooled neonates. Pediatr Int. 2013;55(2):169-76.

40 Tokuhisa T, Ibara S, Minakami H, Maede Y, Ishihara C, Matsui T. Outcome of infants with hypoxic ischemic encephalopathy treated with brain hypothermia. J Obstet Gynaecol Res. 2015 Feb;41(2):229-37.

41 Cainelli E, Trevisanuto D, Cavallin F, Manara R, Suppiej A. Evoked potentials predict psychomotor development in neonates with normal MRI after hypothermia for hypoxic-ischemic encephalopathy. Clin Neurophysiol. 2018 Jun;129(6):1300-6.

42 Dereymaeker A, Matic V, Vervisch J, Cherian PJ, Ansari AH, De Wel O, et al. Automated EEG background analysis to identify neonates with hypoxic-ischemic encephalopathy treated with hypothermia at risk for adverse outcome: A pilot study. Pediatr Neonatol. 2019 Feb;60(1):50-8

43 Fitzgerald MP, Massey SL, Fung FW, Kessler SK, Abend NS. High electroencephalographic seizure exposure is associated with unfavorable outcomes in neonates with hypoxic-ischemic encephalopathy. Seizure. 2018 Oct;61: 221-6.

44 Watanabe K, Miyazaki S, Hara K, Hakamada S. Behavioral state cycles, background EEGs and prognosis of newborns with perinatal hypoxia. Electroencephalogr Clin Neurophysiol. 1980 Sep;49(5-6):618-25.

45 Murray DM, Boylan GB, Ryan CA, Connolly S. Early EEG findings in hypoxic-ischemic encephalopathy predict outcomes at 2 years. Pediatrics. 2009 Sep;124(3):e459-67.

46 Lamblin MD, André M, Challamel MJ, CurziDascalova L, d'Allest AM, De Giovanni E, et al. Electroencephalography of the premature and term newborn: maturational aspects and glossary. Neurophysiol Clin. 1999 Apr;29(2): 123-219.
47 Pressler RM, Boylan GB, Morton M, Binnie CD, Rennie JM. Early serial EEG in hypoxic ischaemic encephalopathy. Clin Neurophysiol. 2001 Jan;112(1):31-7.

48 Tsuchida TN, Wusthoff CJ, Shellhaas RA, Abend NS, Hahn CD, Sullivan JE, et al. American clinical neurophysiology society standardized EEG terminology and categorization for the description of continuous EEG monitoring in neonates: report of the American Clinical Neurophysiology Society critical care monitoring committee. J Clin Neurophysiol. 2013;30(2):161-73.

49 Burton VJ, Gerner G, Cristofalo E, Chung SE, Jennings JM, Parkinson C, et al. A pilot cohort study of cerebral autoregulation and 2-year neurodevelopmental outcomes in neonates with hypoxic-ischemic encephalopathy who received therapeutic hypothermia. BMC Neurol. 2015 Oct;15(1):209.

50 Nevalainen P, Lauronen L, Metsaranta M, Lonnqvist T, Ahtola E, Vanhatalo S. Neonatal somatosensory evoked potentials persist during hypothermia. Acta Paediatr. 2017;106(6): 912-7.

51 Garfinkle J, Sant'Anna GM, Rosenblatt B, Majnemer A, Wintermark P, Shevell MI. Somatosensory evoked potentials in neonates with hypoxic-ischemic encephalopathy treated with hypothermia. Eur J Paediatr Neurol. 2015;19(4):423-8.

52 Al Amrani F, Marcovitz J, Sanon PN, Khairy M, Saint-Martin C, Shevell M, et al. Prediction of outcome in asphyxiated newborns treated with hypothermia: is a MRI scoring system described before the cooling era still useful? Eur J Paediatr Neurol. 2018;22(3): 387-95.

53 Ancora G, Testa C, Grandi S, Tonon C, Sbravati F, Savini S, et al. Prognostic value of brain proton MR spectroscopy and diffusion tensor imaging in newborns with hypoxic-ischemic encephalopathy treated by brain cooling. Neuroradiology. 2013 Aug;55(8):101725.

54 Barta H, Jermendy A, Kolossvary M, Kozak LR, Lakatos A, Meder U, et al. Prognostic value of early, conventional proton magnetic resonance spectroscopy in cooled asphyxiated infants. BMC Pediatr. 2018 Sep;18(1):302.

55 Chalak LF, DuPont TL, Sanchez PJ, Lucke A, Heyne RJ, Morriss MC, et al. Neurodevelopmental outcomes after hypothermia therapy in the era of Bayley-III. J Perinatol. 2014; 34(8):629-33.

56 Charon V, Proisy M, Bretaudeau G, Bruneau B, Pladys P, Beuchée A, et al. Early MRI in neonatal hypoxic-ischaemic encephalopathy treated with hypothermia: prognostic role at 2-year follow-up. Eur J Radiol. 2016 Aug; 85(8):1366-74

57 Massaro AN, Evangelou I, Fatemi A, Vezina G, Mccarter R, Glass P, et al. White matter tract integrity and developmental outcome in newborn infants with hypoxic-ischemic encephalopathy treated with hypothermia. Dev Med Child Neurol. 2015 May;57(5):441-8.
58 Mulkey SB, Yap VL, Swearingen CJ, Riggins MS, Kaiser JR, Schaefer GB. Quantitative cranial magnetic resonance imaging in neonatal hypoxic-ischemic encephalopathy. Pediatr Neurol. 2012 Aug;47(2):101-8.

59 Schreglmann M, Helps S, Hart D, Vollmer B. Two-year behavioural outcome of children who underwent therapeutic hypothermia for neonatal hypoxic ischaemic encephalopathy. Dev Med Child Neurol. 2016;58:23-4.

60 Shankaran S, Barnes PD, Hintz SR, Laptook AR, Zaterka-Baxter KM, McDonald SA, et al.; Eunice Kennedy Shriver National Institute of Child Health and Human Development Neonatal Research Network. Brain injury following trial of hypothermia for neonatal hypoxicischaemic encephalopathy. Arch Dis Child Fetal Neonatal Ed. 2012 Nov;97(6):F398-404.

61 Trivedi SB, Vesoulis ZA, Rao R, Liao SM, Shimony JS, McKinstry RC, et al. A validated clinical MRI injury scoring system in neonatal hypoxic-ischemic encephalopathy. Pediatr Radiol. 2017 Oct;47(11):1491-9.

62 Tusor N, Wusthoff C, Smee N, Merchant N, Arichi T, Allsop JM, et al. Prediction of neurodevelopmental outcome after hypoxicischemic encephalopathy treated with hypothermia by diffusion tensor imaging analyzed using tract-based spatial statistics. Pediatr Res. 2012 Jul;72(1):63-9.

63 Weeke LC, Groenendaal F, Mudigonda K, Blennow M, Lequin MH, Meiners LC, et al. A novel magnetic resonance imaging score predicts neurodevelopmental outcome after perinatal asphyxia and therapeutic hypothermia. J Pediatr. 2018 Jan;192:33-40.e2

64 Barkovich AJ, Hajnal BL, Vigneron D, Sola A, Partridge JC, Allen F, et al. Prediction of neuromotor outcome in perinatal asphyxia: evaluation of MR scoring systems. AJNR Am J Neuroradiol. 1998 Jan;19(1):143-9.

65 Rutherford MA, Pennock JM, Counsell SJ, Mercuri E, Cowan FM, Dubowitz LM, et al. Abnormal magnetic resonance signal in the internal capsule predicts poor neurodevelopmental outcome in infants with hypoxic-ischemic encephalopathy. Pediatrics. 1998 Aug; 102(2 Pt 1):323-8.

66 van Rooij LG, Toet MC, van Huffelen AC, Groenendaal F, Laan W, Zecic A, et al. Effect of treatment of subclinical neonatal seizures detected with aEEG: randomized, controlled trial. Pediatrics. 2010 Feb;125(2):e358-66.

67 Bednarek N, Mathur A, Inder T, Wilkinson J, Neil J, Shimony J. Impact of therapeutic hypothermia on MRI diffusion changes in neonatal encephalopathy. Neurology. 2012 May; 78(18):1420-7.

68 Alderliesten T, de Vries LS, Khalil Y, van Haastert IC, Benders MJ, Koopman-Esseboom C, et al. Therapeutic hypothermia modifies perinatal asphyxia-induced changes of the corpus callosum and outcome in neonates. PLoS One. 2015 Apr;10(4):e0123230. 
69 Alderliesten T, de Vries LS, Staats L, van Haastert IC, Weeke L, Benders MJ, et al. MRI and spectroscopy in (near) term neonates with perinatal asphyxia and therapeutic hypothermia. Arch Dis Child Fetal Neonatal Ed. 2017 Mar;102(2):F147-52.

70 Heursen EM, Zuazo Ojeda A, Benavente Fernández I, Jimenez Gómez G, Campuzano Fernández-Colima R, Paz-Expósito J, et al. Prognostic Value of the Apparent Diffusion Coefficient in Newborns with Hypoxic-Ischaemic Encephalopathy Treated with Therapeutic Hypothermia. Neonatology. 2017; 112(1):67-72.

71 Al Amrani F, Kwan S, Gilbert G, Saint-Martin C, Shevell M, Wintermark P. Early imaging and adverse neurodevelopmental outcome in asphyxiated newborns treated with hypothermia. Pediatr Neurol. 2017 Aug;73:20-7.

72 Mitra S, Kendall GS, Bainbridge A, Sokolska M, Dinan M, Uria-Avellanal C, et al. Proton magnetic resonance spectroscopy lactate/Nacetylaspartate within 2 weeks of birth accurately predicts 2 -year motor, cognitive and language outcomes in neonatal encephalopathy after therapeutic hypothermia. Arch Dis Child Fetal Neonatal Ed. 2019 Jul; 104(4):F424-32.
73 Sijens PE, Wischniowsky K, Ter Horst HJ. The prognostic value of proton magnetic resonance spectroscopy in term newborns treated with therapeutic hypothermia following asphyxia. Magn Reson Imaging. 2017 Oct;42: 82-7.

74 Gerner GJ, Burton VJ, Poretti A, Bosemani T, Cristofalo E, Tekes A, et al. Transfontanellar duplex brain ultrasonography resistive indices as a prognostic tool in neonatal hypoxicischemic encephalopathy before and after treatment with therapeutic hypothermia. J Perinatol. 2016;36(3):202-6.

75 D'Alton GD, Berkowitz RL, Bienstock J, Ghidini A, Goldsmith J, Higgins R, et al. Executive summary: neonatal encephalopathy and neurologic outcome, second edition - report of the American College of Obstetricians and Gynecologists' Task Force on Neonatal Encephalopathy. Obstet Gynecol. 2014;123(4): 896-901.

76 Robertson CM, Perlman M. Follow-up of the term infant after hypoxic-ischemic encephalopathy. Paediatr Child Health. 2006 May; 11(5):278-82.
77 O'Shea TM. Diagnosis, treatment, and prevention of cerebral palsy. Clin Obstet Gynecol. 2008 Dec;51(4):816-28.

78 Del Río R, Ochoa C, Alarcon A, Arnáez J, Blanco D, García-Alix A. Amplitude Integrated Electroencephalogram as a Prognostic Tool in Neonates with Hypoxic-Ischemic Encephalopathy: A Systematic Review. PLoS One. 2016 Nov; 11(11):e0165744.

79 Sánchez Fernández I, Morales-Quezada JL, Law S, Kim P. Prognostic Value of Brain Magnetic Resonance Imaging in Neonatal Hypoxic-Ischemic Encephalopathy: A Meta-analysis. J Child Neurol. 2017 Nov;32(13):1065-73.

80 Zou R, Xiong T, Zhang L, Li S, Zhao F, Tong $\mathrm{Y}$, et al. Proton magnetic resonance spectroscopy biomarkers in neonates with hypoxicischemic encephalopathy: A systematic review and meta-analysis. Front Neurol. 2018 Aug;9(AUG):732.

81 Morgan C, Romeo DM, Chorna O, Novak I, Galea C, Del Secco S, et al. The Pooled Diagnostic Accuracy of Neuroimaging, General Movements, and Neurological Examination for Diagnosing Cerebral Palsy Early in HighRisk Infants: A Case Control Study. J Clin Med. 2019 Nov;8(11):E1879. 